\title{
NUMERICAL SIMULATION OF MECHANICAL PROPERTIES OF SERIES SYSTEM WITH BEARING AND PIER UNDER LATERAL LOAD
}

\author{
ZHENHUA DONG ${ }^{1,2}$, JINQUAN ZHANG ${ }^{1,2^{*}}$, \\ SHOUSHAN CHENG ${ }^{1,2}$, PENGFEI LI ${ }^{1,2}$ \\ ${ }^{1}$ Bridge and Tunnel Research Center, Research Institute of Highway Science \\ of Transport Ministry, Beijing, China \\ ${ }^{2}$ Key Laboratory of Old Bridge Inspection and Reinforcement Technology \\ Industry, Beijing, China
}

Received 23 August 2019; accepted 19 October 2020

\begin{abstract}
The local series system with typical common plate rubber support/pier in highway reinforced concrete girder bridge is the object of the current research. The finite element numerical simulation method is used to study sensitive parameters - the mechanical properties of the series system under the horizontal load. The simulated results show that the interface bonding strength between the bearing and adjacent structure is reduced; the equivalent shear deformation and the horizontal force of bearing under horizontal load change insignificantly with the increase of horizontal displacement. However, the total shear deformation and equivalent shear deformation increase with the increase of the axial compression ratio. In addition, the top horizontal force and displacement of the pier significantly decrease with reduction of the connection strength at both ends of the bearing. Therefore, adjusting the axial compression ratio of the pier and
\end{abstract}

\footnotetext{
* Corresponding author. E-mail: rioh_jqzhang@163.com 
interfacial connection mode can obviously affect the mechanical properties of the support and adjacent structure, even the failure mode of the local structure. This approach can help estimate the mechanical properties of the existing bridge and determine the reasonable maintenance plan.

Keywords: common plate rubber support, highway reinforced concrete girder bridge, mechanical property, sensitive parameters, series system.

\section{Introduction}

The ordinary plate rubber bearing, as a typical form of support in highway reinforced concrete (RC) medium and small span girder bridges in China, mainly supports the superstructure and transmits the load on the span to the substructure, while ensuring free deformation at the ends of the bridge structure under action of load, temperature, humidity, concrete shrinkage, and horizontal and rotational displacements. The bearing is connected with the bridge pier to form a local series system. Under the coupling action of vehicle load and environmental climatic conditions, interface slip, opening, locking, shear deformation, curling, etc. usually occur in the common plate rubber support. These diseases can cause change in the stiffness of the local structure and lead to uneven stiffness distribution in the whole structure. This may affect the failure mode of a bridge under earthquake and vehicle load and increase potential risk and uncertainty with regard to structure safety, complicating estimation of the mechanical behaviour of the serviced girder bridge system. Therefore, development of a reasonable mechanical model and analysis are used as a basic theoretical support in order to accurately estimate the performance indexes of the serviced bridges.

In the related design guide of highway bridges in China (JTG/T B0201-2008), the mechanical performance indexes of single components of rubber bearing and bridge pier are respectively considered, however, the interaction of components in the series system with common plate rubber support and bridge pier is not addressed. As long as the damage of single components and interface connection in a girder bridge becomes more prominent under earthquake and vehicle load, the interface slip and shear performance of laminated rubber bearing are studied continuously. However, since the geometric structure and connection conditions of the tested rubber support are significantly different from the common plate rubber support in the serviced bridge, the mechanical behavior and failure modes are also obviously different. While the structure integrity design and estimation are emphasized and studied on a regular basis, the mechanical performance of the local and the whole structure is analyzed by applying the realistic 
connection stiffness model without contact interface slip. In view of the shear performance and interface contact situation of common palate rubber bearing, the mechanical performance and related factors of the local series system should be further studied. That will allow to accurately estimate the mechanical behavior and formulate the effective reinforcement and maintenance renovation scheme of the serviced girder bridge system.

At present, considering structural characteristics of the ordinary plate rubber support, its typical mechanical performance is studied by applying the horizontal monotone test, quasi-static cycle test and numerical simulation method considering such parameters as shear deformation, shear stiffness, and friction. The results show that the friction parameter is reduced with the increase of vertical pressure on the support, and the interface friction slip can decrease the effective shear deformation of rubber bearing. Various initial shear stiffness models were proposed and modified (Buckle, Nagarajaiah, \& Ferrell, 2002; Cardone \& Perrone, 2010; Chen, Tian, Yan, \& Kim, 2014; Gauron et al., 2018; Han et al., 2017; Li et al., 2014; Montuori et al., 2016; Wu et al., 2017 Xing et al., 2016; Wu et al., 2014; Yamamoto et al., 2009), in which the effects of interfacial friction slip performance was not considered. The interface friction sliding is a typical failure characteristic of the common plate rubber support, thus the interface friction energy dissipation in the support is further studied under the horizontal cycle load. The test specimens of the ordinary plate rubber support are commonly fixed at the load board by bolts and the bottom surface of bearing slid - at the steel plate. Because the size of the test supports is larger (more than $450 \mathrm{~mm}$ ) and unilateral or bilateral fixing is used at the ends of supports, the interface connection strength and lateral stiffness of supports obviously increase. The research results show that the ultimate shear strain of supports is more than $150 \%$, the failure phenomena of shear deformation, curling, opening and interface friction slip are produced, and interface friction slip can increase the seismic energy dissipation in the rubber support (Konstantinidis et al., 2008; Saadatnia et al., 2019; Kikuchi et al., 2010; Xing and Li, 2017; Yan et al., 2017). The above conclusions are used to analyse the seismic performance of a bridge structure with seismic laminated rubber support, and then the impact of the interface contact situation and shear performance of the rubber support on the failure modes and mechanics of the adjacent structure are emphasized. However, a fine model of the local series system with supports, interface connections and bridge piers is rarely developed, so there is a certain lack of research in this area.

Based on the mechanical properties of the laminated damping rubber bearing, Du et al. proposed the mechanic model of isolation series system
Numerical Simulation of Mechanical Properties of Series System With Bearing and Pier Under Lateral Load 
by using the bending-shear model of the RC column and deduced the lateral stiffness calculation equations of the laminated rubber support, RC column and series system by using the direct integration method under the coupling actions of the axial pressure and lateral load. The results showed that the horizontal stiffness of the isolation series system decreased with the increase of the height ratio and axial pressure load (Du et al., 2011; Du et al., 2013; Khan et al., 2019). Based on the study of Haringx and Gent, Zhou et al. (1999) proposed a mechanic model, horizontal stiffness and critical load equations of the isolation series system. The factors related to the material, axial pressure and bending performance of the bearing were accounted for in the equations. In the above mechanic equations, the interface friction slip performance of the support and the damage behaviour of the column are not considered. It is not consistent with the connection construction characteristics of the medium and small span girder bridge with common plate rubber bearing. Therefore, the mechanical behaviour and factors of the series system with common plate rubber bearing and bridge pier should be further studied, and applicability of the existing mechanics models therein should be verified.

In this study, the mechanic equations of the series system with isolation supports and columns are deduced, and the relevant sensitive parameters are proposed, such as geometrical configuration of the ordinary plate rubber bearing, axial compressive ratio of the column and interface connection condition between the support and the adjacent structural members. In order to analyse the impact of these factors on the performance of the superstructure and substructure in the series system, the finite-element numerical simulation method is used to form the fine numerical model of the series system with common plate rubber bearing, interface friction contact situation and RC bridge pier.

\section{Mechanical model of series system}

Under the action of axial pressure and horizontal load, the high damping rubber bearing and bridge pier undergo bending and shear deformation. On the basis of horizontal force equilibrium condition, the mechanical equation of the series system without interfacial friction slip between the bearing and bridge pier is expressed as follows:

$$
K_{\mathrm{R}}(P) f_{\mathrm{R}}=K_{\mathrm{c}}(P) f_{\mathrm{c}},
$$

where $f_{\mathrm{R}}$ is the lateral displacement at the top of the bearing; $f_{\mathrm{C}}$ is the lateral displacement at the top of the bridge pier; $K_{\mathrm{R}}(P)$ is the shear stiffness of the bearing, and $K_{\mathrm{C}}(P)$ is the lateral stiffness of the $\mathrm{RC}$ column. 
The equation of $f_{\mathrm{R}}$ is described by

$$
f_{\mathrm{R}}=f_{\mathrm{RM}}+f_{\mathrm{RQ}} \text {, }
$$

where $f_{\mathrm{RM}}$ and $f_{\mathrm{RQ}}$ is the lateral displacement caused by bending deformation and shear deformation, respectively.

In case of a typical common plate rubber support in the small and medium span RC girder bridge in China, the total height and the rubber layer thickness are smaller than the high damping rubber bearing, and the shear capacity and shear deformation are mainly mechanical indexes of the common support. Thus, omitting the horizontal displacement caused by bending deformation of the support, horizontal displacement is expressed as

$$
\begin{gathered}
f_{\mathrm{R}}=f_{\mathrm{RQ}}, \\
f_{\mathrm{RQ}}=f_{\mathrm{S}}+f_{\mathrm{B}},
\end{gathered}
$$

where $f_{\mathrm{S}}$ is sliding displacement of the bearing; $f_{\mathrm{B}}$ is the relative displacement between the bottom and top of the bearing.

Based on macro lateral force-displacement curves of the bearing, the effective shear stiffness of the bearing is calculated as Eq. (5) without sliding displacement.

$$
K_{\mathrm{ER}}(P)=\frac{F_{\mathrm{S}}}{f_{\mathrm{B}}},
$$

where $F_{\mathrm{S}}$ is the lateral force at the top of the bearing.

The theoretical shear stiffness of the common plate rubber bearing is described by Eq. (6), and it is given by constant axial pressure stress of $10 \mathrm{MPa}$ and without interface friction slip, in which the factors of geometry construction and shear modulus of rubber material are taken into account:

$$
K_{\mathrm{R}}=\frac{G_{\mathrm{R}} A_{\mathrm{R}}}{\sum t},
$$

where $\Sigma t$ represents the rubber thickness of bearing; $G_{\mathrm{R}}$ is the shear elastic module of bearing; $A_{\mathrm{R}}$ is shear area of bearing. The initial lateral stiffness $K_{\mathrm{C}}(P)$ of the bridge pier is expressed by Eq. (7) corresponding to the yield situation:

$$
K_{\mathrm{C}}(P)=K_{\mathrm{y}}=\frac{F_{\mathrm{y}}}{\Delta_{\mathrm{y}}}=\frac{3 M_{\mathrm{y}}}{L^{3} \varphi_{\mathrm{y}}},
$$

where $F_{\mathrm{y}}$ is horizontal force at the top of the bridge pier; $\Delta_{\mathrm{y}}$ is the top horizontal displacement of the bridge pier; $M_{\mathrm{y}}$ is the yield moment of cross section in the plastic hinge region $; \varphi_{\mathrm{y}}$ is the curvature of cross section in the plastic hinge region; $L$ is the effective height of the bridge pier.
Numerical Simulation

of Mechanical

Properties of Series

System With Bearing and Pier Under

Lateral Load 
After the bridge pier yields, the plastic deformation occurs. So, the later stiffness is obtained by Eq. (8).

$$
K_{\mathrm{C}}(P)=\frac{K_{y}}{\mu_{i}^{0.4}},
$$

where $\mu_{i}$ represents the displacement ductility coefficient of the pier at the $i$-th loading stage.

If the anchor connection is used between the bearing and pier, the lateral stiffness of the series system of $K_{S}(P)$ is given by Eq. (9).

$$
K_{\mathrm{S}}(P)=\frac{K_{\mathrm{R}}(P) K_{\mathrm{C}}(P)}{K_{\mathrm{R}}(P)+K_{\mathrm{C}}(P)} .
$$

The mechanical model of the series system is initially obtained from the seismic performance analysis of the high-rise building, the anchor connection is applied between the column and laminated rubber support. The lateral deformation of components in the series system is co-ordinately developed, therefore, the mechanic relationship of the series system is described by Eq. (10):

$$
\frac{f_{\mathrm{C}}}{f_{\mathrm{R}}}=\frac{K_{\mathrm{R}}(P)}{K_{\mathrm{C}}(P)} .
$$

For a medium and small span girder bridge with common plate rubber supports, the lateral stiffness of supports is far less than for bridge piers in the series system, and their mechanical relationship is impacted by interface connection situation and shear stiffness of supports. When the interface contact is strong, the mechanic relationship meets Eq. (11).

$$
\frac{f_{\mathrm{C}}}{f_{\mathrm{R}}}=\frac{K_{\mathrm{S}}(P)}{K_{\mathrm{C}}(P)}
$$

When the interface friction slip occurs, the effective shear stiffness of support is applied, so the mechanical relationship of series system is expressed by Eq. (12).

$$
\frac{f_{\mathrm{C}}}{f_{\mathrm{R}}}=\frac{K_{\mathrm{ER}}(P)}{K_{\mathrm{C}}(P)}
$$

In summary, the interface contact condition between support and adjacent structure can obviously affect the mechanical relationships of the series system, at the same time, it also affects the shear force and shear deformation of the rubber support. According to the horizontal force equilibrium condition, it further affects the mechanics of the bridge pier. Therefore, in order to verify the applicability and accuracy of the 
above conclusions and mechanic models, the finite element numerical simulation for the series system with common plate rubber supports is further carried out.

\section{Finite element numerical simulation of the series system}

\subsection{Finite-element model of the series system}

The finite-element analysis software ABAQUS is used to establish a three-dimensional solid model of the series system with a common plate rubber bearing and bridge pier, as shown in Figure 1. The construction properties of the simulated bridge pier are shown in Table 1 . The bridge pier adopts the ideal elastic-plastic damage model with Poisson ratio of 0.2 and elastic modulus of $2.05 \cdot 10^{4} \mathrm{MPa}$. The tensile failure of the concrete is not considered. The pier, base and cap are the C3D8R units. The size of the base is $1000 \mathrm{~mm} \times 1500 \mathrm{~mm} \times 500 \mathrm{~mm}$; the size of the cap beam is $6000 \mathrm{~mm} \times 600 \mathrm{~mm} \times 500 \mathrm{~mm}$. In the finite element model of the series system, the base, cap beam and loading plate are a rigid body. At the bottom of the base, the fix boundary is applied; and the top of the loading plate is free in the loading direction.

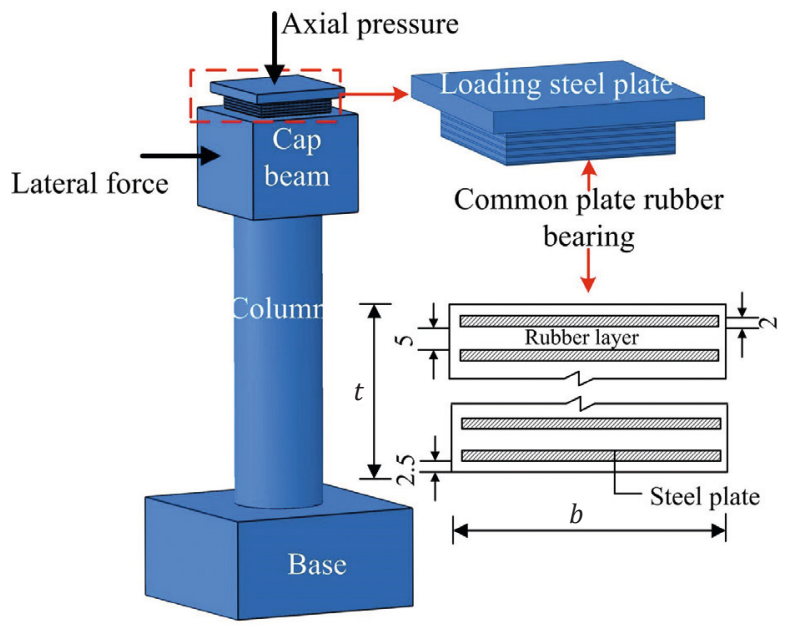

Figure 1. Finite-element model of the series system
Pengfei $L i$

Numerical Simulation of Mechanical Properties of Series System With Bearing and Pier Under Lateral Load 
Table 1. Properties of cross-section of the simulated bridge pier

\begin{tabular}{cccccccc}
\hline Number & $\boldsymbol{L}, \mathbf{m}$ & $\boldsymbol{D}, \mathbf{m m}$ & $\boldsymbol{\sigma}_{\mathrm{c}}, \mathbf{M P a}$ & $\boldsymbol{\sigma}_{\mathbf{y}, \mathbf{M P a}}$ & $\boldsymbol{\rho}_{\mathbf{s},} \%$ & $\boldsymbol{\sigma}_{\mathbf{s y}}, \mathbf{M P a}$ & $\boldsymbol{\rho}_{\mathbf{s v},} \%$ \\
\hline 1 & 1.75 & 450 & 18.3 & 330 & 1.47 & 330 & 0.7 \\
\hline
\end{tabular}

Note: $L$ - height of the bridge pier; $D$ - diameter of the cross section; $\sigma_{c}-$ compressive stress of concrete; $\sigma_{y}$ - yield strength of a longitudinal rebar; $\rho_{s}$ - reinforcement ratio of longitudinal bars; $\sigma_{\mathrm{sy}}$-yield strength of a stirrup; $\rho_{\mathrm{sv}}$ - reinforcement ratio of stirrups.

In the bridge pier model, the rebar corresponds to ideal elasticplastic model with Poisson ratio of 0.3 , yield strength of $330 \mathrm{MPa}$, ultimate strength of $400 \mathrm{MPa}$ and elastic modulus of $2.0 \cdot 10^{5} \mathrm{MPa}$; the rebar is T3D2 unit (truss element). The reinforcement cage in the bridge pier is embedded in the concrete column; the bond slip between the steel bar and concrete is not considered. The rubber layer of the bearing uses the C3D8RH hybrid element and the steel plate layer contains a C3D8R unit.

The cross-section width of the square common plate rubber support is $400 \mathrm{~mm}$; its total height is $84 \mathrm{~mm}$; the total thickness of the rubber layers is $60 \mathrm{~mm}$; thickness of a single steel plate is $2.5 \mathrm{~mm}$; thickness of a single rubber layer is $5 \mathrm{~mm}$; the shear stiffness of support is $2059 \mathrm{kN} / \mathrm{m}$ according to Eq. (6). The tie connection between the steel plate and rubber layer is applied ignoring the tearing of the steel plate and rubber layer. The one-order strain energy function of the MooneyRivlin model is adopted for the rubber layer, and it is expressed by Eq. (13).

$$
U=C_{10}\left(I_{1}-3\right)+C_{01}\left(I_{2}-3\right),
$$

where $U$ is the strain energy; $C_{10}$ and $C_{01}$ are Rivlin coefficients; $I_{1}$ and $I_{2}$ are the first and second Green strain invariants, respectively. The model can accurately describe the mechanical properties of the rubber material with shear deformation of less than $150 \%$. According to the test shear performance of the rubber bearing, the rubber parameters of $C_{10}=0.35 \mathrm{MPa}$ and $C_{01}=0.03 \mathrm{MPa}$ are selected.

In view of the connection conditions between the common plate rubber bearing and the adjacent structure in the serviced medium and small span girder bridge in China, the tie connection and friction contact are considered in this study. It is divided into symmetric tie connection, symmetric friction contact and asymmetric situation with tie connection and friction contact. The tie connection unit and the interface friction contact unit are used. The classical Coulomb friction theory is applied to the interface friction contact element. 
In this work, the axial pressure is firstly applied on the top of the

Numerical Simulation of Mechanical Properties of Series loading plate and kept at a constant value, and then the unidirectional horizontal displacement is monotonously exerted at the lateral side of the loading plate step by step. The loading schema is shown in System With Bearing and Pier Under Figure 1.

\subsection{Simulation cases}

The parameters of interface contact modes at both ends of the bearing and axial compression ratio of the pier are mainly considered. The interface contact mode includes symmetric contact and asymmetric contact, i.e. friction contact, tie connection and combination of tie and friction connection at both ends of the bearing. According to the interface contact situation between the rubber layer and steel plate, and concrete, the friction coefficient is 0.1 and 0.2 , respectively. According the axial pressure ratio regulations in the design guide of the highway bridges, it is commonly less than 0.2 , so the axial compression ratio is $0.1,0.15$ and 0.2 , respectively. Specific simulation cases are shown in Table 2. $\mu$ stands for friction coefficient.

Table 2. Specific simulation cases

\begin{tabular}{cccc}
\hline $\begin{array}{c}\text { Case } \\
\text { number }\end{array}$ & $\begin{array}{c}\text { Connection type at } \\
\text { the top } \\
\text { of bearing }\end{array}$ & $\begin{array}{c}\text { Connection type } \\
\text { at the bottom } \\
\text { of bearing }\end{array}$ & $\begin{array}{c}\text { Axial } \\
\text { compression } \\
\text { ratio }\end{array}$ \\
\hline T1-1 & Tie & Tie & 0.20 \\
\hline T2-1 & Tie & Tie & 0.15 \\
\hline T3-1 & Tie & Tie & 0.10 \\
\hline F1-1 & Friction, $\mu=0.2$ & Friction, $\mu=0.2$ & 0.20 \\
\hline F1-2 & Friction, $\mu=0.1$ & Friction, $\mu=0.1$ & 0.20 \\
\hline F2-1 & Friction, $\mu=0.2$ & Friction, $\mu=0.2$ & 0.15 \\
\hline F2-2 & Friction, $\mu=0.1$ & Friction, $\mu=0.1$ & 0.15 \\
\hline F3-1 & Friction, $\mu=0.2$ & Friction, $\mu=0.2$ & 0.10 \\
\hline F3-2 & Friction, $\mu=0.1$ & Friction, $\mu=0.1$ & 0.10 \\
\hline C1-1 & Friction, $\mu=0.2$ & Tie & 0.20 \\
\hline C1-2 & Friction, $\mu=0.1$ & Tie & 0.20 \\
\hline C2-1 & Friction, $\mu=0.2$ & Tie & 0.15 \\
\hline C2-2 & Friction, $\mu=0.1$ & Tie & 0.15 \\
\hline C3-1 & Friction, $\mu=0.2$ & Tie & 0.10 \\
\hline C3-2 & Friction, $\mu=0.1$ & Tie & 0.10 \\
\hline
\end{tabular}




\section{Simulation results analysis and discussion}

\subsection{Analysis of mechanical performance of the bearing}

The results of the total shear deformation, effective shear deformation, shear stiffness and frictional sliding displacement of the bearing are analyzed respectively. The total shear deformation of the support is composed of the support slip and the effective shear deformation, it is expressed by Eq. (14).

$$
\gamma=\gamma_{\mathrm{S}}+\gamma_{\mathrm{R}}=\frac{f_{\mathrm{S}}}{\sum t}+\frac{f_{\mathrm{R}}}{\sum t}
$$

where $\gamma_{S}$ represents shear strain caused by bearing sliding; $\gamma_{R}$ is the effective shear strain caused by relative displacement between the top and bottom of the bearing. In seismic design code of the highway bridges in China, under the earthquake, the effective shear strain of $\gamma_{R}$ should be less than $100 \%$.

\subsubsection{Shear deformation of the bearing}

Symmetric anchor connection at both ends of the bearing

When the support is anchored with the upper and lower adjacent members, the lateral displacement at the top and bottom of the support, the lateral displacement of the loading plate, the top displacement of the pier, and the relative displacement between the upper and lower ends of the support correspond to axial pressure ratio of $0.1,0.15,0.2$, respectively, as shown in Figure 2. Figure 2 shows that the top lateral displacement of the support is consistent with the superstructure and the bottom lateral displacement of the support is the same as the top lateral displacement of the bridge pier. Before the shear strain of the support reaches $100 \%$ corresponding the loading lateral displacement of $60 \mathrm{~mm}$, the relative lateral displacement between the upper and lower ends of the support increases with the increase of the lateral displacement of loading. After that, the effective shear strain does not increase and the maximum value is $40 \%$. In addition, the total shear strain and the effective shear strain increase with the increase of the axial pressure ratio.

In this case, the bridge pier produces plastic deformation. The top lateral displacement is over the theoretical yield displacement of $6.86 \mathrm{~mm}, 7.28 \mathrm{~mm}, 7.7 \mathrm{~mm}$ corresponding to the axial pressure ratio of $0.1,0.15,0.2$, respectively. When the bridge pier yields, the maximum total shear deformation of the bearing is $50 \%$ under axial compression ratio of 0.2 , and the effective shear deformation is $36.7 \%$; 


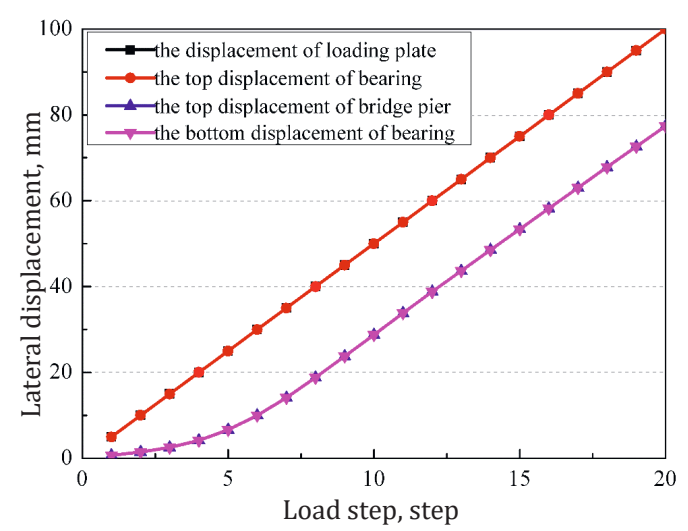

a) axial compression ratio of 0.1

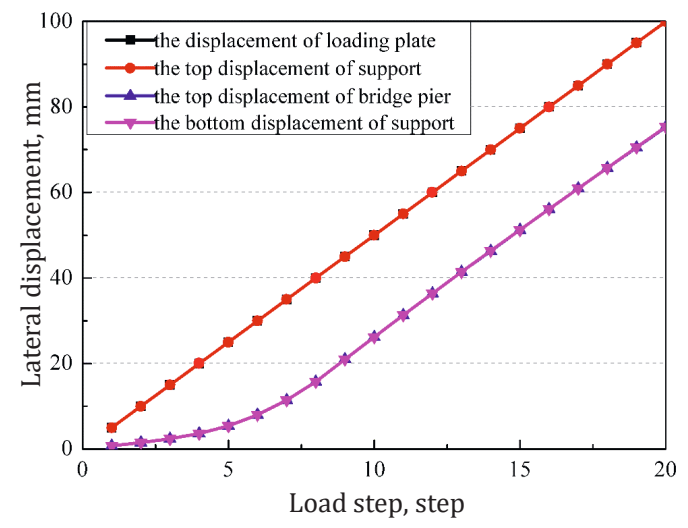

c) axial compression ratio of 0.2

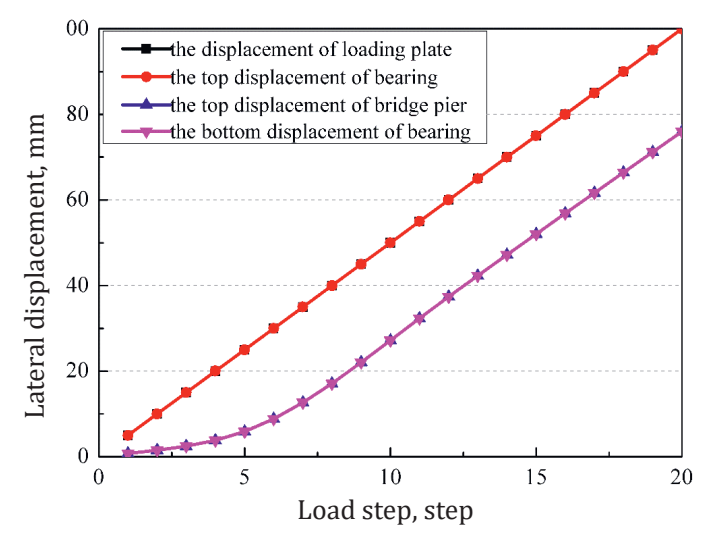

b) axial compression ratio of 0.15

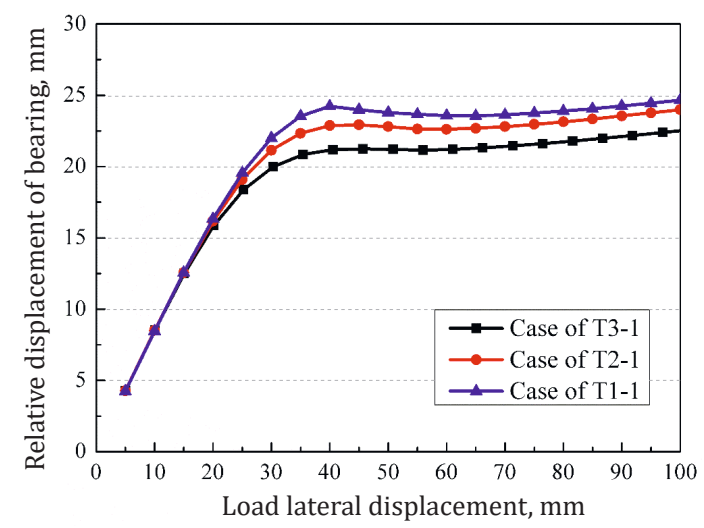

d) the relative displacement of the bearing

Figure 2. Lateral displacement of the series system under anchor connection at both ends of the bearing

when the compression strain of concrete in the plastic hinge zone of the bridge pier is 0.008 , the total shear deformation is $83.3 \%$, and the corresponding effective shear deformation is $40 \%$.

\section{Symmetrical friction contact at both ends of the bearing}

The symmetrical friction contact is applied at both ends of the bearing, the friction coefficient is 0.1 . The lateral displacement of the support, the loading plate and the bridge pier, and the relative displacement of the support under unidirectional horizontal load are shown in Figure 3. As shown in Figure 3, because the friction slip occurs at contact interface, the linearity of relative lateral displacement 
between the bearing and adjacent components increases with the increase of loading lateral displacement; while the linearity of relative lateral displacement between the top and bottom ends of the support also increases. The axial pressure ratio is more than 0.15 , and then the relative lateral displacement of the support obviously rises, however, the maximum effective shear strain is $30 \%$ corresponding to the total shear strain of $100 \%$. Besides, the top lateral displacement of the bridge pier is significantly reduced, therefore, the interface friction slip can decrease the damage to substructure.

The symmetrical friction contact with the friction coefficient of 0.2 is applied at both ends of the bearing. The lateral displacement of the

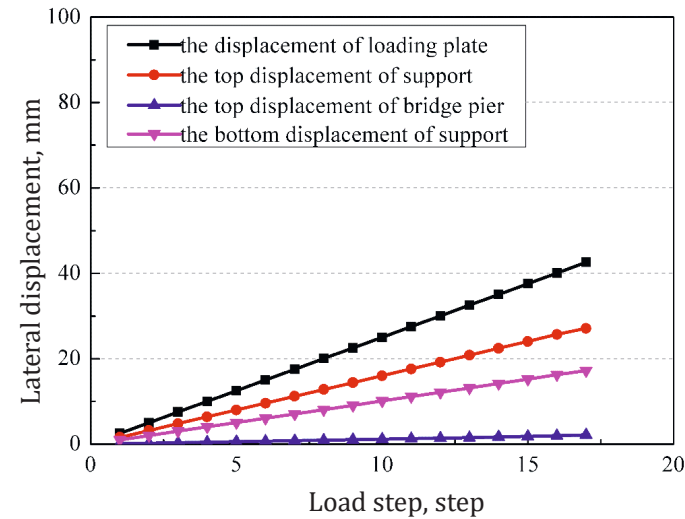

a) axial compression ratio of 0.1

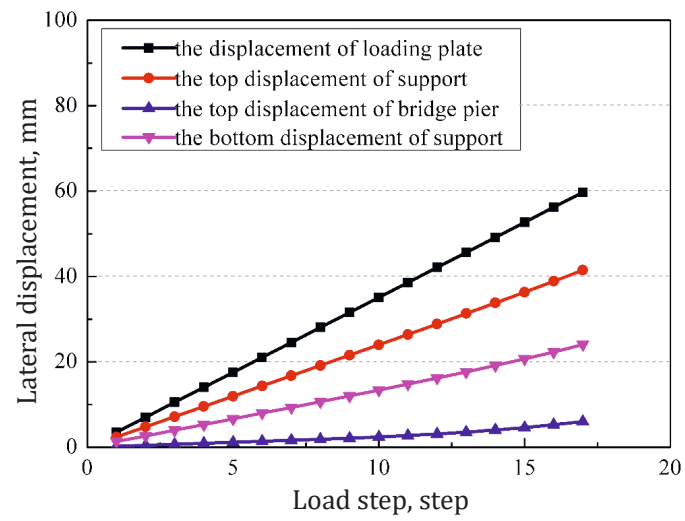

c) axial compression ratio of 0.2

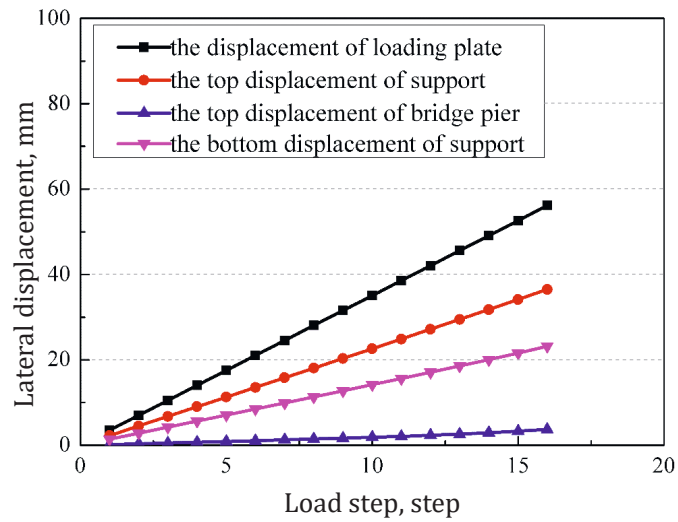

b) axial compression ratio of 0.15

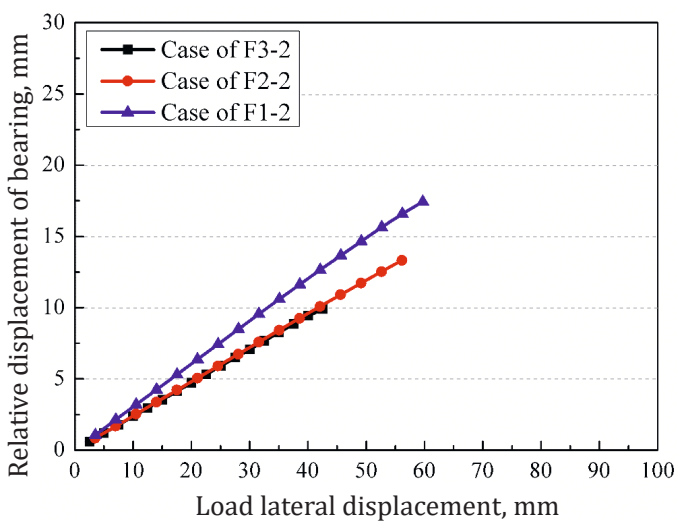

d) the relative displacement of the bearing

Figure 3. Lateral displacement of the series system with friction coefficient of 0.1 at both ends of the bearing 


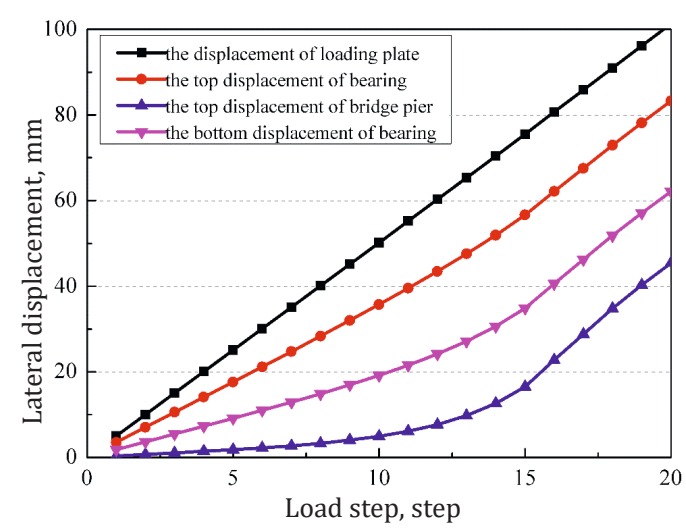

a) axial compression ratio of 0.1

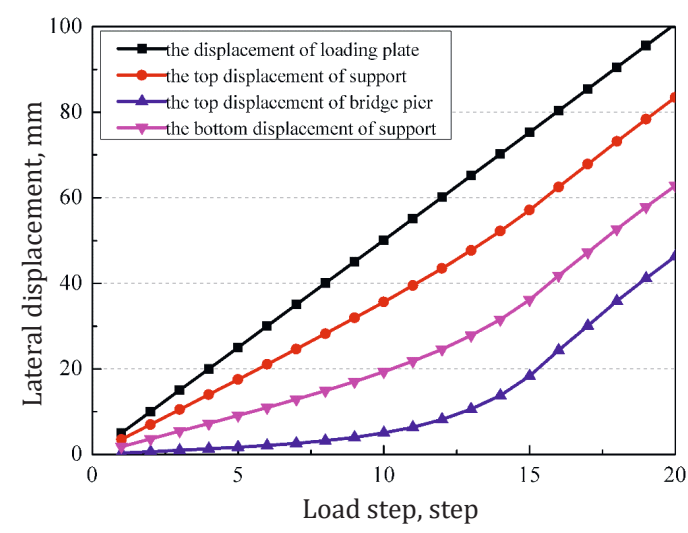

c) axial compression ratio of 0.2

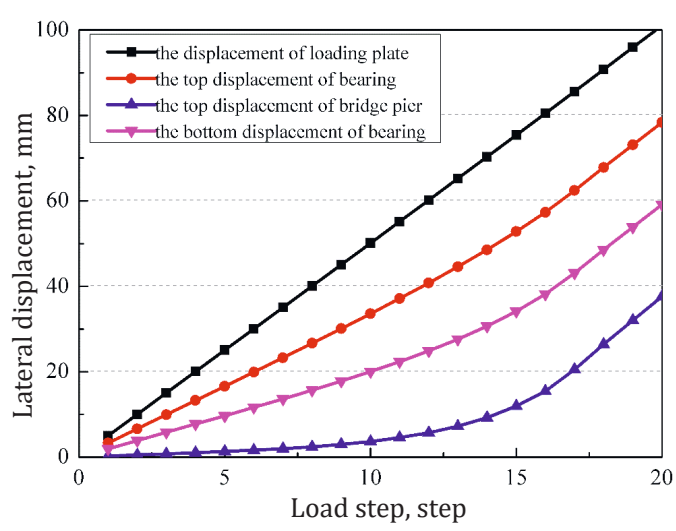

b) axial compression ratio of 0.15

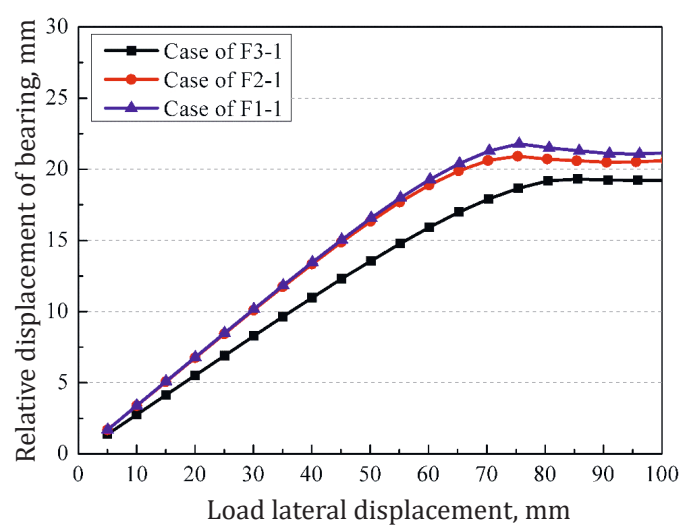

d) the relative displacement of the bearing

Figure 4. Lateral displacement of the series system with friction coefficient of 0.2 at both ends of the bearing

support, the loading plate and the pier, and the relative displacement of the support under unidirectional horizontal load are shown in Figure 4. The results in Figure 4 show that before the total shear strain reaches $100 \%$, the linearity of relative lateral displacement between the support and adjacent components rises, i.e., after that, there is no change. That is the same as the development trend of the relative lateral displacement between the upper and lower ends of the support. In addition, the effective shear strain of the support increases with the increase of the axial pressure ratio, and the maximum value is about $32 \%$.

In this case, the top lateral displacement of the bridge pier is over the theoretical yield displacement and reaches the theoretical ultimate 
displacement corresponding to the ultimate concrete compression strain of 0.008 . Therefore, the interface friction contact is strengthened, and then the effective shear strain of the support and the top lateral displacement of the bridge pier is increased.

\section{Asymmetric interface contact situation at both ends of the bearing}

The anchor connection is applied to the bottom interface of the support, and the friction contact with friction efficient of 0.1 is used at the top interface of the support. The lateral displacement of the support, the loading plate and the pier under unidirectional horizontal load are shown in Figure 5. Figure 5 shows that because the friction slip occurs at the contact interface, the relative lateral displacement between the top

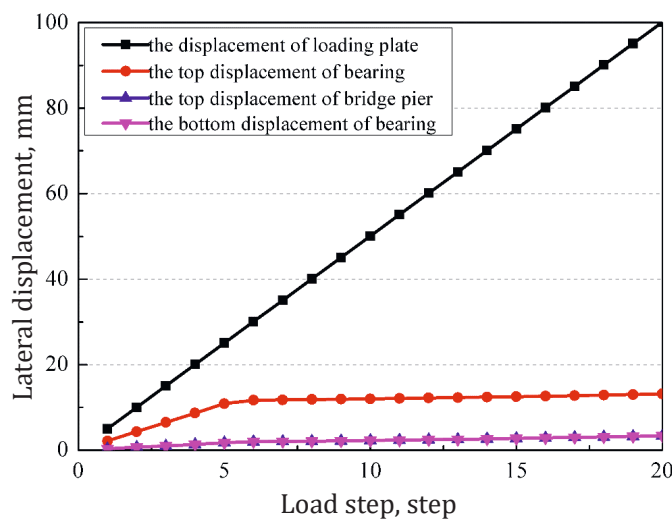

a) axial compression ratio of 0.1

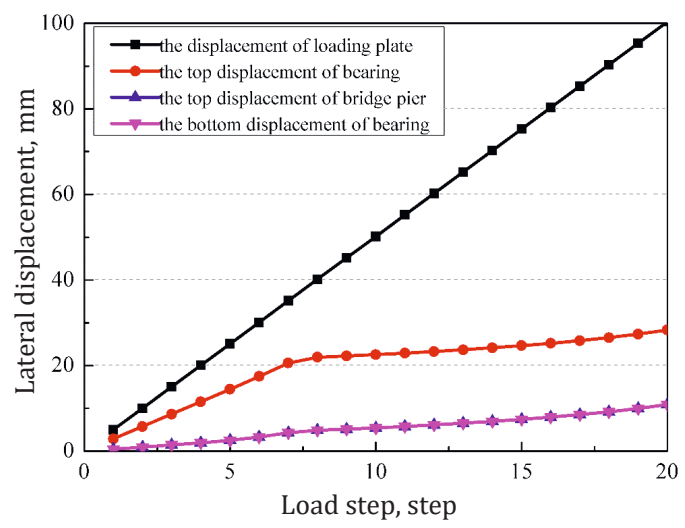

c) axial compression ratio of 0.2

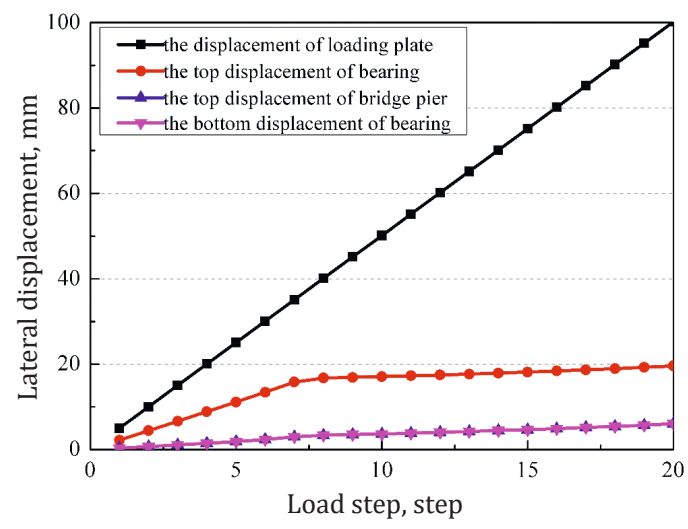

b) axial compression ratio of 0.15

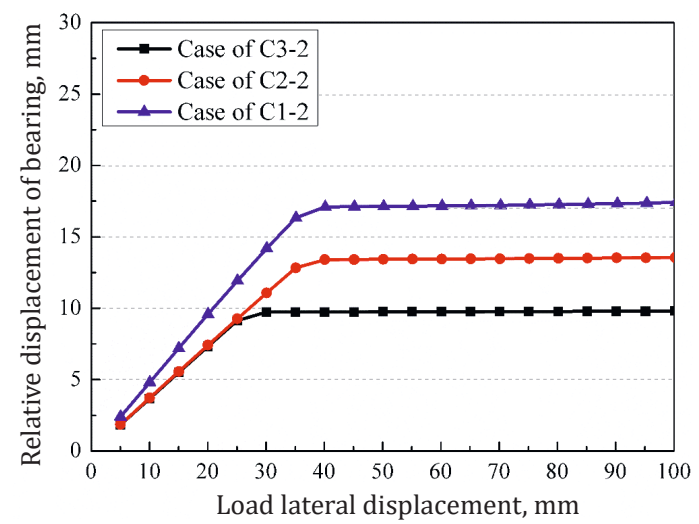

d) the relative displacement of the bearing

Figure 5. Lateral displacement of the series system with friction coefficient of 0.1 at the upper ends of the bearing 
of the support and superstructure loading plate is gradually increased with the increase of loading lateral displacement. However, the lateral displacement at the bottom surface of the support is consistent with that of the top of the bridge pier, that is, no relative lateral displacement occurs. Furthermore, the relative displacement of the support rises with the increase of the axial compressive ratio, and the maximum effective shear strain of the support is $28.3 \%$ corresponding to the axial pressure ratio of 0.2 and the total shear strain of $66.7 \%$. After that, there is no increase.

In this case, because the friction slip occurs at the contact interface at the top of the support, it can reduce the horizontal force of the
Numerical Simulation of Mechanical

Properties of Series System With Bearing and Pier Under Lateral Load

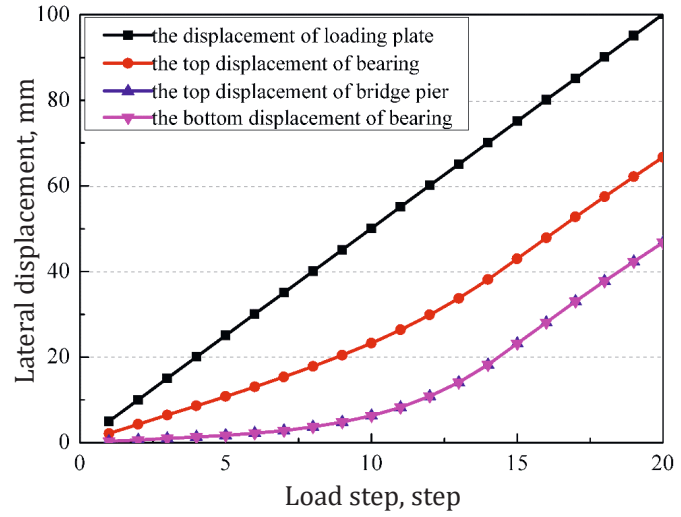

a) axial compression ratio of 0.1

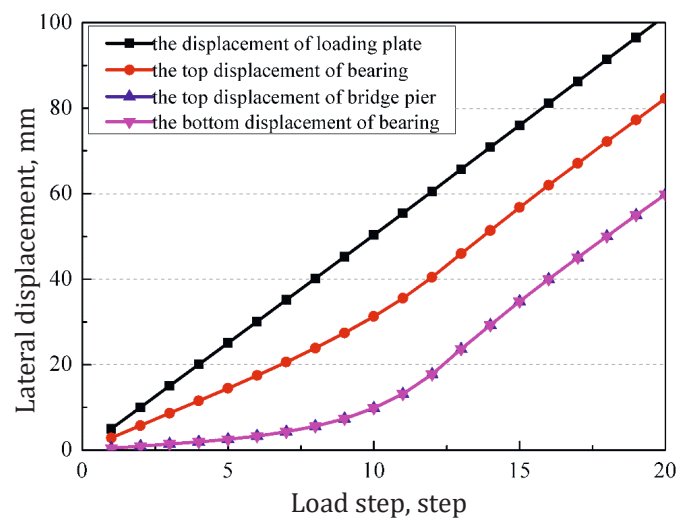

c) axial compression ratio of 0.2

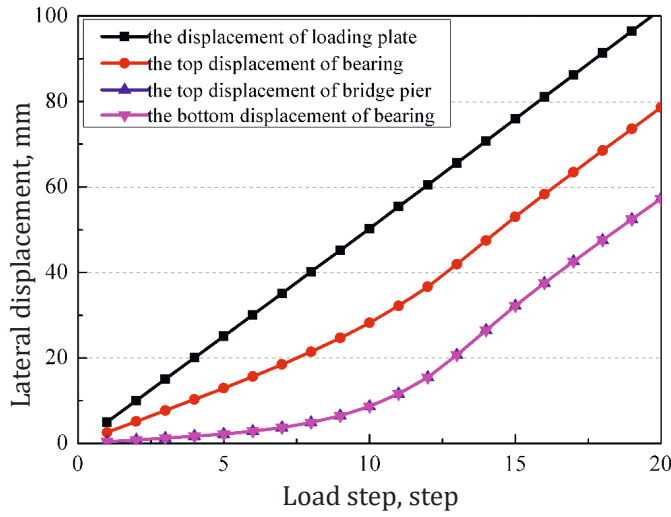

b) axial compression ratio of 0.15

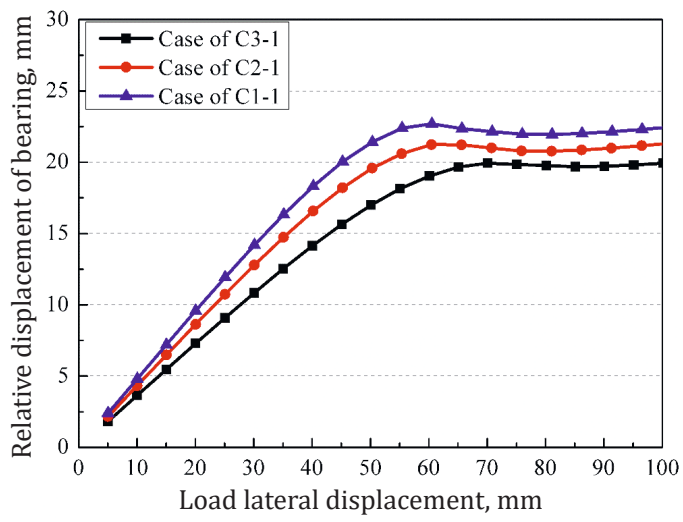

d) the relative displacement of the bearing

Figure 6. Lateral displacement of the series system with friction coefficient of 0.2 at the upper ends of the bearing 
substructure, so the lateral top displacement of the bridge pier is lower than yield displacement, especially for the case under the axial compressive ratio of less than 0.2 .

The anchor connection is applied at the bottom of the support and the friction contact with friction coefficient of 0.2 is used at the top of the support. The lateral displacement curves under unidirectional horizontal load are shown in Figure 6. Figure 6 shows that the development trends of the relative lateral displacement between the support and adjacent components, and the top lateral displacement and damage situation of the bridge pier are basically consistent with the results shown in Figure 4, corresponding to the case with symmetric friction contact with friction coefficient of 0.2 . In addition, the effective shear strain of the support increases with the increase of the axial pressure ratio, and the maximum value is $34 \%$ corresponding to the axial pressure ratio of 0.2 and the total support shear strain of $116.7 \%$.

\subsubsection{Lateral force-displacement curves of the bearing}

The horizontal force displacement curves of the support with the anchorage connection at both ends of the bearing are shown in Figure 7. As shown in Figure 7, before the total shear strain reaches $50 \%$, the horizontal force linearity increases with the increase of loading displacement, and then it steady reaches the maximum value of $48.73 \mathrm{kN}$ corresponding to the total shear strain of $66.7 \%$. After that, the horizontal force decreases and tends to the straight line. In addition, the horizontal force increases with the increase of the axial compression ratio.

The symmetrical friction contact between the support and adjacent components is applied, and the value of friction coefficient is 0.1 and 0.2 , respectively. The horizontal force displacement curves of the support are shown in Figure 8. The results in Figure 8 shows that for the case with friction coefficient of 0.1 , the horizontal force displacement curves of the support increase linearly until the interface friction slip crossing the whole interface section. The maximum horizontal force is $34.86 \mathrm{kN}$ corresponding to the axial pressure ratio of 0.2 . For the case with friction coefficient of 0.2 , before the total shear strain reaches $116.7 \%$, the linearity of the horizontal force of the support slowly increases, and then the maximum horizontal force is $42.69 \mathrm{kN}$ corresponding to the axial pressure ratio of 0.2 . After that, it reduces because of the friction interface opening and slip. Therefore, the increase of the interface friction coefficient can improve the lateral resistance of the support.

The asymmetric interface connections between the support and adjacent structure are applied, in which the interface friction contact is used at the top of the support, friction coefficient is 0.1 and 0.2 , 


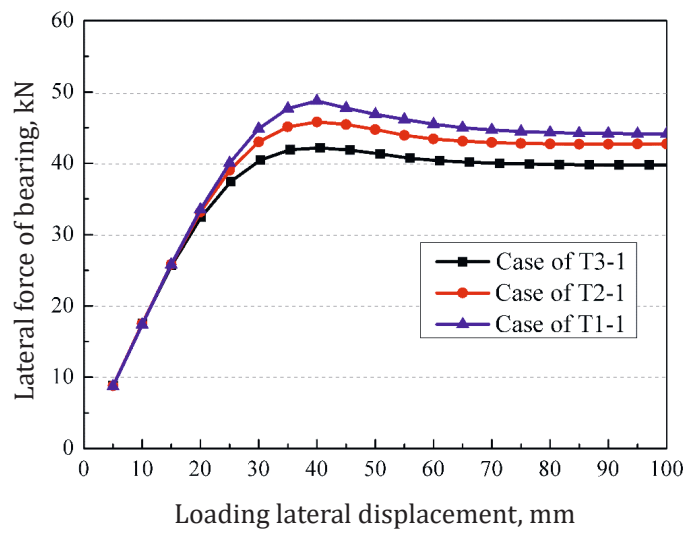

Figure 7. Comparisons of horizontal force-displacement curves under anchor connection at both ends

respectively, and the tie connection is applied at the bottom of the support. The horizontal force-displacement curves of the support are shown in Figure 9. The results in Figure 9 show that for the case with friction coefficient of 0.1 , before the total shear strain of the support reaches $66.7 \%$, the horizontal force-displacement curves of the support increase linearly, and then the maximum horizontal force is $35 \mathrm{kN}$ corresponding to the axial pressure ratio of 0.2 . After that, horizontal force does not increase. For the case with friction coefficient
Numerical Simulation of Mechanical Properties of Series System With Bearing and Pier Under Lateral Load

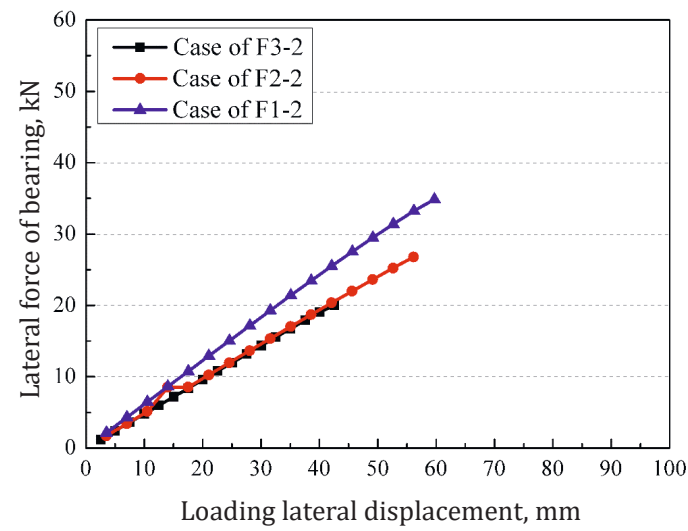

a) friction coefficient of 0.1

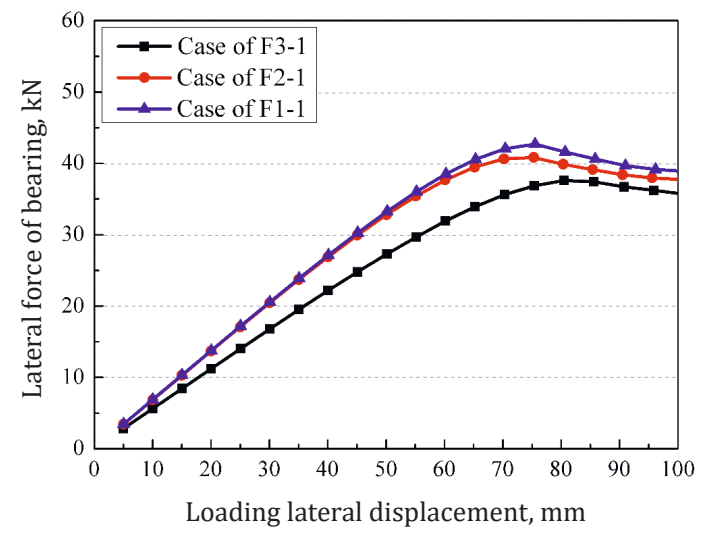

b) friction coefficient of 0.2

Figure 8. Comparisons of horizontal force displacement curves under symmetry friction connection at both ends 


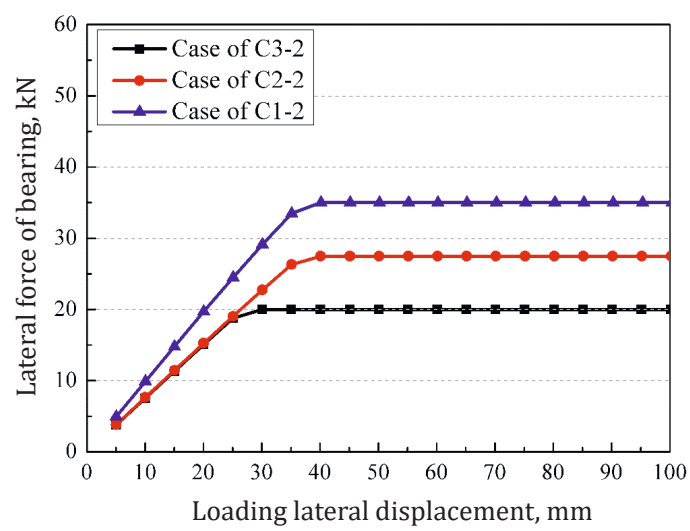

a) friction coefficient of 0.1

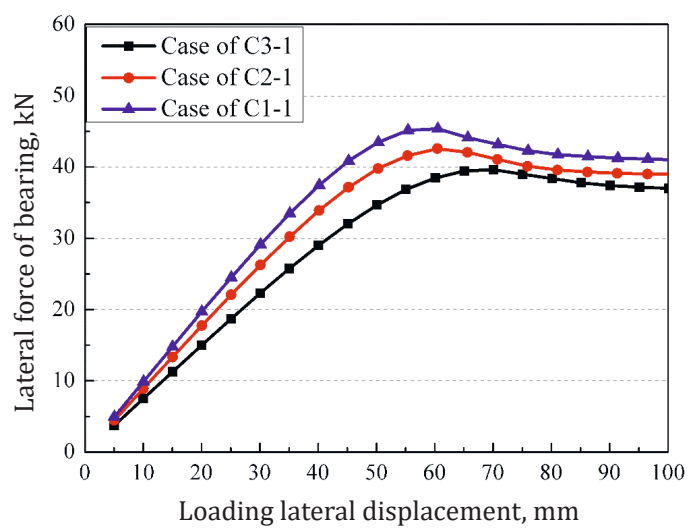

b) friction coefficient of 0.2

Figure 9. Comparisons of horizontal force-displacement curves under asymmetry connection at both ends of the bearing

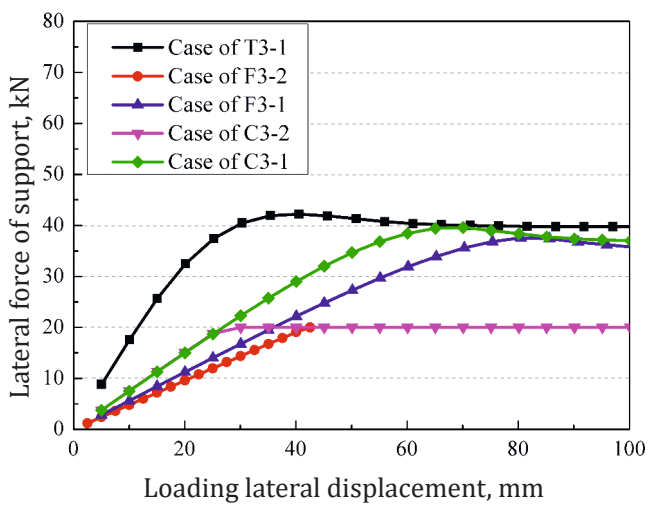

a) axial compression ratio of 0.1

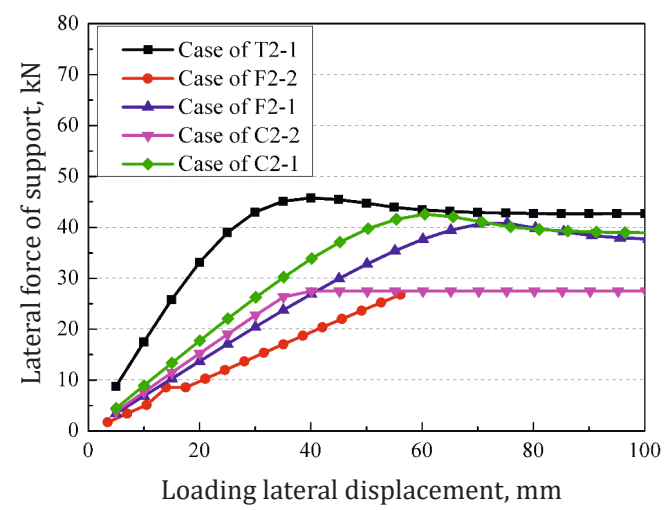

b) axial compression ratio of 0.15

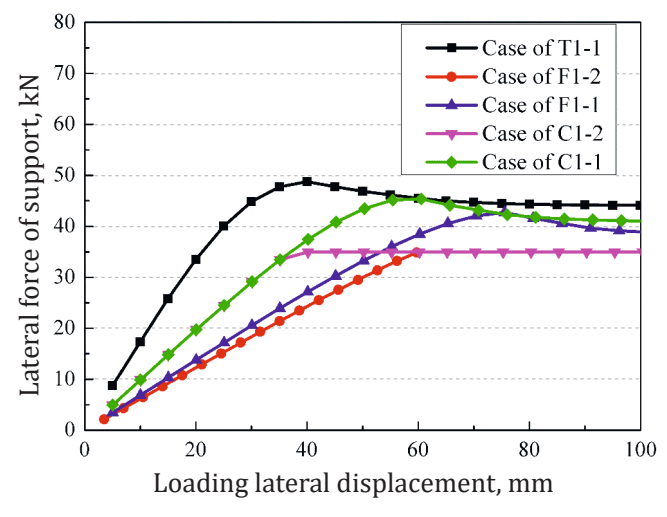

c) axial compression ratio of 0.2

Figure 10. Comparison of the horizontal force of the bearing 
of 0.2 , before the total shear strain reaches $100 \%$, the linearity of the horizontal force of the support slowly increases, and then the maximum horizontal force is $45.35 \mathrm{kN}$ corresponding to the axial pressure ratio of 0.2. After that, it reduces because of friction interface opening and slip.

The horizontal force displacement curves of the supports under different interface contact conditions are compared, as shown in Figure 10. Figure 10 shows that according to the value of the maximum lateral force, the case with tie connection at both ends of the support, its horizontal force is maximum. Next, it is the case with asymmetric tie connection and friction contact with friction coefficient of 0.2 . However, if friction coefficient of 0.1 is applied at the top of the support, under horizontal load, the interface contact slip can occur easily, so the horizontal force is smaller than in the case with strength contact. In summary, the interface connection situation can obviously affect the horizontal force and the effective shear strain of the support.

\subsection{Lateral force-displacement of bridge piers}

Under different interface connection modes between the support and adjacent structure, the horizontal force-displacement curves of the bridge pier are shown in Figure 11, and the calculated results of the horizontal force and displacement of the bridge pier in yield and ultimate state are shown in Table 2-4.

As shown in Figure 11, for the case with tie connection and interface friction coefficient of 0.2 , the lateral force and lateral displacement are larger than in the case with interface friction coefficient of 0.1. So, the interface contact situation is strengthened, and then the horizontal load on superstructure can be transmitted to the substructure. While the contact interface produces friction slip early, the lateral force and displacement of the bridge pier decreases.

The results in Table 2-4 show that the lateral force and displacement of the bridge pier corresponding to the yield and ultimate state increase with the increase of the axial pressure ratio, and the maximum values occur in the case with symmetric tie connection at both ends of the support corresponding to axial pressure ratio of 0.2 . For the case with tie connection and friction coefficient of 0.2 , the interface connection is strengthened, and then the bridge pier can reach the yield and ultimate state under the horizontal load. When the interface friction coefficient is 0.1 , the horizontal resistance reduces, and then the horizontal force and displacement of the bridge pier is lower.

In summary, the interface connection strength of supports increases, the horizontal force on the superstructure is transmitted to the bridge pier, and then the horizontal force and deformation of the pier increase
Numerical Simulation of Mechanical Properties of Series System With Bearing and Pier Under Lateral Load 


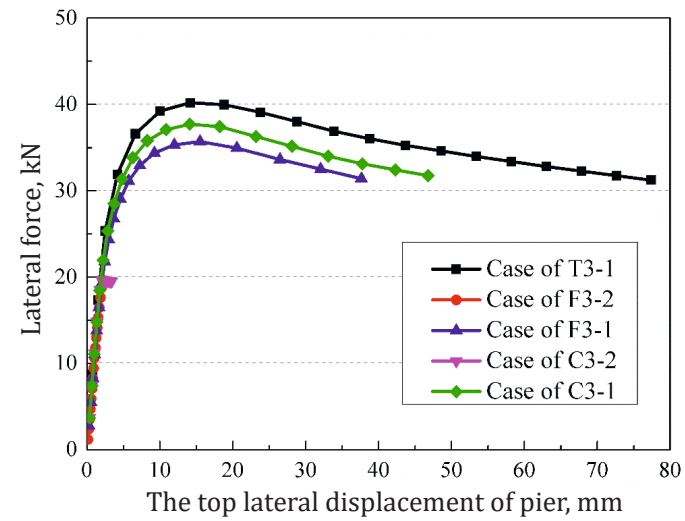

a) axial compression ratio of 0.1

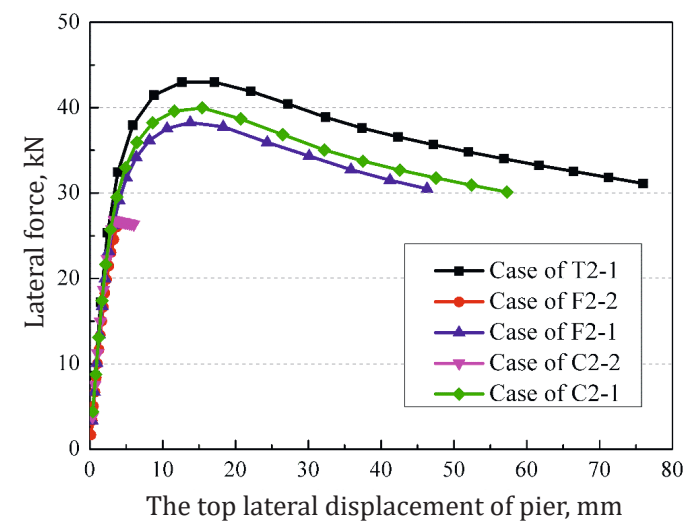

b) axial compression ratio of 0.15

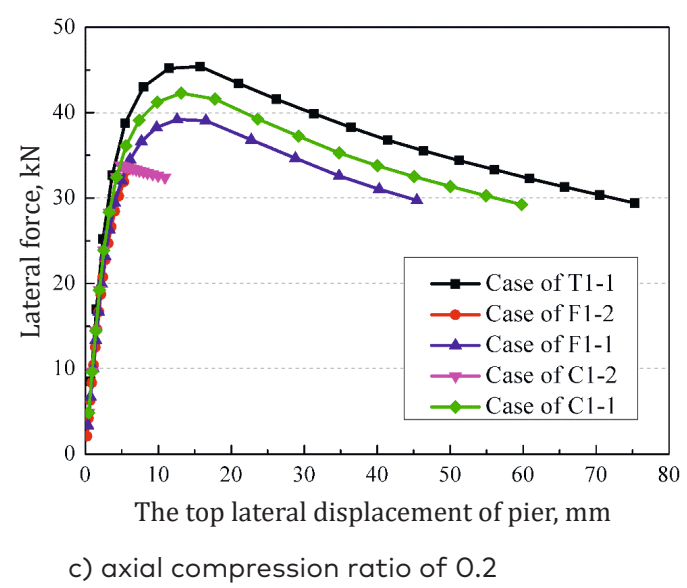

Figure 11. Comparisons of horizontal force-displacement curves of the pier

significantly. On the contrary, the interface connection strength between the support and adjacent structures decreases, and the horizontal force and deformation of the pier reduce, which can prevent or alleviate the damage of the bridge pier. In addition, in order to avoid collapse, upper structure collision and beam falling, superstructure sliding should be restricted by improving the interface connection strength. Therefore, it is necessary to determine the reasonable mechanics of the series system and the interface connection mode between supports and piers to ensure the structural integrity. 
Table 2. Horizontal force of the series system under anchor connection at both ends

\begin{tabular}{ccccccc}
\hline \multirow{2}{*}{$\begin{array}{c}\text { Axial } \\
\begin{array}{c}\text { compression } \\
\text { ratio }\end{array}\end{array}$} & $\begin{array}{c}\text { Lateral } \\
\text { displacement, } \\
\mathbf{m m}\end{array}$ & $\begin{array}{c}\text { Lateral } \\
\text { force, } \\
\mathbf{k N}\end{array}$ & $\begin{array}{c}\text { Top } \\
\text { displacement } \\
\text { of the bearing, } \\
\mathbf{m m}\end{array}$ & $\begin{array}{c}\text { Ultimate } \\
\text { displacement, } \\
\mathbf{m m}\end{array}$ & $\begin{array}{c}\text { Ultimate } \\
\text { force, } \\
\mathbf{k N}\end{array}$ & $\begin{array}{c}\text { Top } \\
\text { displacement } \\
\text { of the bearing, } \\
\mathbf{m m}\end{array}$ \\
\hline 0.10 & 6.63 & 36.62 & 25 & 18.81 & 39.98 & 40 \\
\hline 0.15 & 7.54 & 41.47 & 30 & 23.57 & 40.45 & 50 \\
\hline 0.20 & 8.00 & 43.04 & 30 & 26.21 & 41.56 & 50 \\
\hline
\end{tabular}

Table 3. Horizontal force of the series system under symmetry friction connection at both ends

\begin{tabular}{|c|c|c|c|c|c|c|c|}
\hline \multirow[b]{2}{*}{ 둔 } & \multirow[b]{2}{*}{ 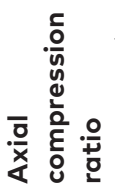 } & \multicolumn{3}{|c|}{ Yield situation of pier } & \multicolumn{3}{|c|}{ Ultimate situation of pier } \\
\hline & & $\begin{array}{c}\text { Lateral } \\
\text { displacement, } \\
\mathrm{mm}\end{array}$ & $\begin{array}{l}\text { Lateral } \\
\text { force, } \\
\text { kN }\end{array}$ & $\begin{array}{c}\text { Top } \\
\text { displacement } \\
\text { of the bearing, } \\
\mathrm{mm}\end{array}$ & $\begin{array}{c}\text { Ultimate } \\
\text { displacement, } \\
\mathrm{mm}\end{array}$ & $\begin{array}{l}\text { Ultimate } \\
\text { force, } k N\end{array}$ & $\begin{array}{c}\text { Top } \\
\text { displacement } \\
\text { of the bearing, } \\
\mathrm{mm}\end{array}$ \\
\hline \multirow{3}{*}{0.1} & 0.10 & - & - & - & - & - & - \\
\hline & 0.15 & - & - & - & - & - & - \\
\hline & 0.20 & - & - & - & - & - & - \\
\hline \multirow{3}{*}{0.2} & 0.10 & 7.23 & 32.94 & 44.6 & 18.09 & 34.97 & 62.44 \\
\hline & 0.15 & 8.17 & 36.17 & 39.52 & 24.36 & 35.92 & 62.53 \\
\hline & 0.20 & 8.47 & 38.27 & 47.58 & 22.75 & 36.8 & 62.12 \\
\hline
\end{tabular}

Table 4. Horizontal force of the series system under asymmetry friction and anchor connection at both ends

\begin{tabular}{|c|c|c|c|c|c|c|c|}
\hline \multirow[b]{2}{*}{$\frac{c}{\frac{n}{c}}$} & \multirow[b]{2}{*}{ 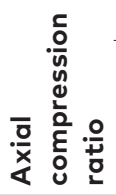 } & \multicolumn{3}{|c|}{ Yield situation of pier } & \multicolumn{3}{|c|}{ Ultimate situation of pier } \\
\hline & & $\begin{array}{c}\text { Lateral } \\
\text { displacement, } \\
\mathrm{mm}\end{array}$ & $\begin{array}{l}\text { Lateral } \\
\text { force, } \\
\text { kN }\end{array}$ & $\begin{array}{c}\text { Top } \\
\text { displacement } \\
\text { of the bearing, } \\
\mathrm{mm}\end{array}$ & $\begin{array}{c}\text { Ultimate } \\
\text { displacement, } \\
\mathrm{mm}\end{array}$ & $\begin{array}{l}\text { Ultimate } \\
\text { force, } \\
\text { kN }\end{array}$ & $\begin{array}{c}\text { Top } \\
\text { displacement } \\
\text { of the bearing, } \\
\mathrm{mm}\end{array}$ \\
\hline \multirow{3}{*}{0.1} & 0.10 & - & - & - & - & - & - \\
\hline & 0.15 & - & - & - & - & - & - \\
\hline & 0.20 & 7.96 & 33.10 & 80.27 & - & - & - \\
\hline \multirow{3}{*}{0.2} & 0.10 & 6.27 & 33.84 & 50.08 & 18.20 & 37.45 & 70.1 \\
\hline & 0.15 & 6.48 & 35.95 & 45.21 & 20.73 & 38.68 & 65.6 \\
\hline & 0.20 & 7.39 & 39.13 & 45.24 & 23.63 & 39.25 & 65.7 \\
\hline
\end{tabular}




\subsection{Mechanic relationships of the series system}

In order to illustrate the impact of interface friction situation on mechanics of the series system, the mechanical relationships of the series system with symmetric interface friction contact at both ends of the support are shown in Figure 12 and 13.

For the series system with the friction coefficient of 0.1 , according to Eq. (10)-(12), the mechanical indexes of the series system are shown in Figure 12. The results in Figure 12 show that the top lateral displacement ratio of the pier to support is similar to the straight line with increase of the horizontal displacement. Because the friction interface slip occurs early under the lateral load, the effective shear

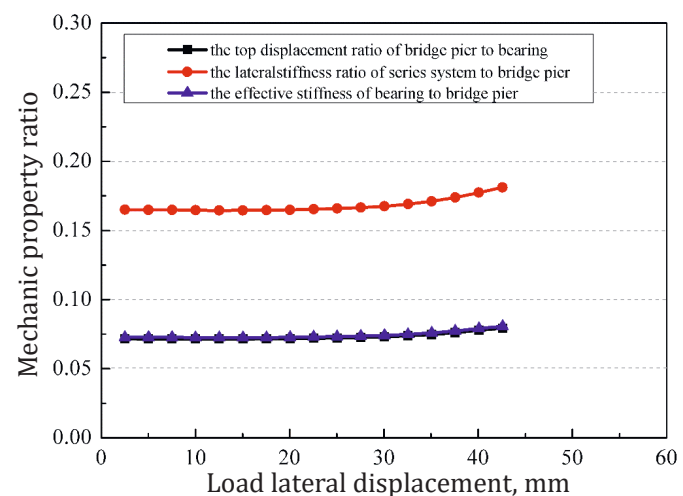

a) axial compression ratio of 0.1

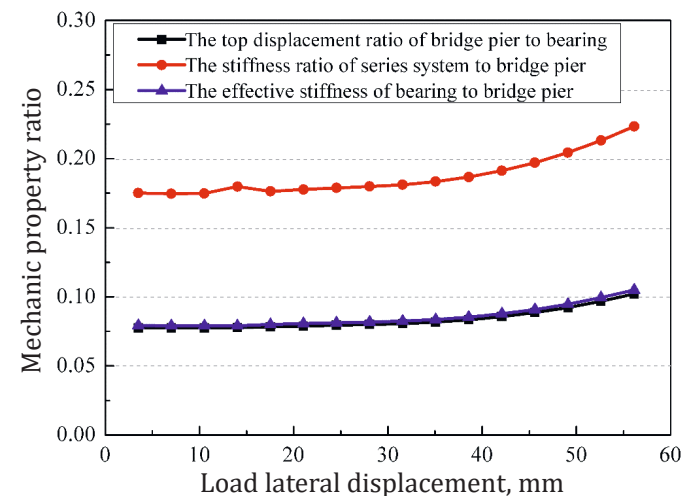

b) axial compression ratio of 0.15

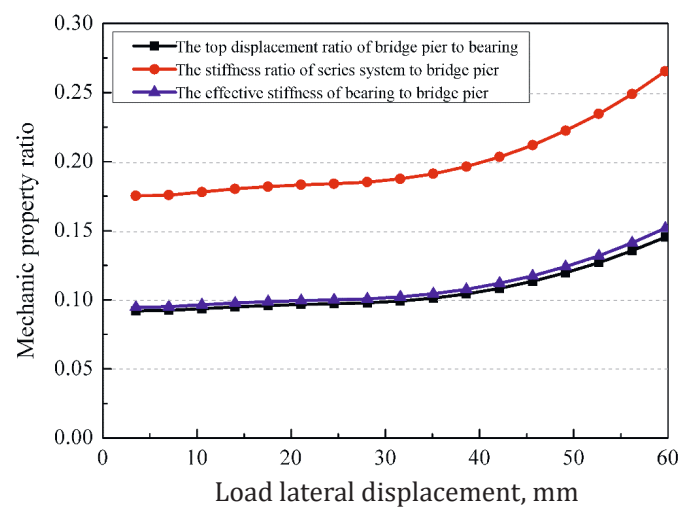

c) axial compression ratio of 0.2

Figure 12. Mechanical properties of the series system with symmetry friction contact of friction coefficient of 0.1 at both ends of the bearing 


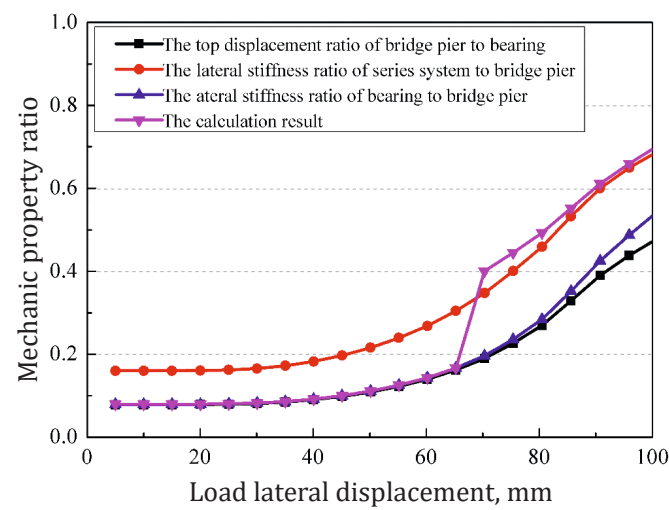

a) axial compression ratio of 0.1

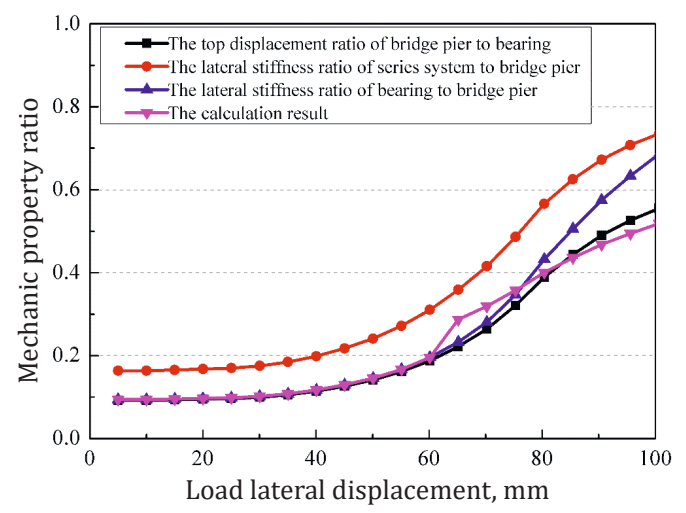

b) axial compression ratio of 0.15

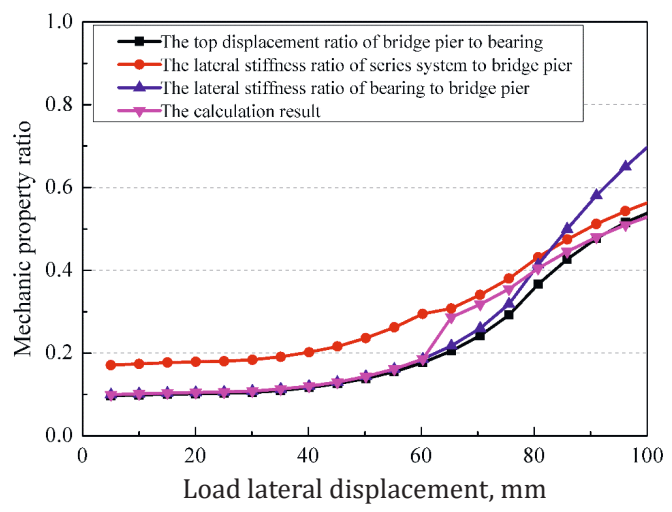

c) axial compression ratio of 0.2

Figure 13. Mechanical properties of the series system with symmetry friction contact of friction coefficient of 0.2 at both ends of the bearing

deformation of the bearing and the top horizontal displacement of the pier is obviously small. In this case, the top displacement ratio of the bridge pier to the bearing is consistent with the effective stiffness ratio, however, it is far less than the lateral stiffness ratio of the series system to the bridge pier. Therefore, for the series system with the obvious interface friction slip, its mechanical properties do not comply with the existing mechanical model of the series system.

For the series system with symmetry friction coefficient of 0.2 , the mechanical index comparison results of series system are shown in Figure 13. The results in Figure 13 show that the maximum difference between the simulated top displacement ratio of the pier to the support and the stiffness ratio of the series system to the pier is $31.8 \%, 25.7 \%$, 
and $19.7 \%$ under the axial pressure ratio of $0.1,0.15,0.2$, respectively. Before the piers reach the yield state, the simulated top displacement ratio is the same as the calculated stiffness ratio of the series system. After the piers yield, the calculated stiffness ratio of the series system suddenly increases, and the maximum difference between the simulated top displacement ratio and the calculated stiffness ratio of the series system is lower than $5 \%$, particularly the series system with the axial pressure ratios of 0.15 and 0.2 . In this case, its mechanical properties can be estimated by the existing mechanical model of the series system.

\section{Conclusions}

Based on the mechanical relationship model of the series system with the laminated rubber bearing and the RC column, the factors and mechanic equations of the series system with different interface connection condition have been proposed. In order to study the mechanics of components in the series system and verify the applicability of mechanic equations, the finite element numerical simulation method was adopted. By analyzing the mechanic indexes of the components and the series system with different interface connection condition, the following conclusions have been drawn.

1. The interface connection condition can obviously affect the total shear strain, the effective shear strain and lateral force of the common plate rubber support. In general, before the total shear strain of support reaches $100 \%$, the relative lateral displacement of the support linearity increases with the increase of loading lateral displacement, and the effective shear strain is lower than $40 \%$. After that, if damage to the bridge pier is produced, or slip occurs the in the contact interface, the effective shear strain of the support does not increase or is reduced. In addition, the effective shear strain and lateral force increase with the increase of the axial pressure ratio.

2. If the interface contact condition is strengthened, the horizontal load on the superstructure can be transmitted to the substructure, and then the lateral force and displacement of the bridge pier are larger than that accompanied with the friction interface slip. Besides, the bridge pier can reach the yield and ultimate state under horizontal load. On the contrary, the interface connection strength between the support and adjacent structures decreases, the horizontal force and deformation of pier reduce, which can prevent or alleviate the damage of the bridge pier. In addition, in order to avoid collapse, upper structure 
collision and beam falling, the superstructure sliding should be restricted by improving the interface connection strength. Therefore, it is necessary to determine the reasonable mechanics of the series system and the interface connection mode between supports and piers to ensure structural integrity.

3. For the series system with the symmetric friction coefficient of 0.1 at both ends of the common plate rubber support, the top lateral displacement ratio of the pier to the support is consistent with the effective stiffness ratio, however, it is lower than the lateral stiffness ratio of the series system to bridge pier. Therefore, for the case with obvious interface friction sliding under the lateral load, its mechanical properties do not comply with the existing mechanical model of the series system. For the series system with the symmetric friction coefficient of 0.2 at both ends of the common plate rubber support, the difference between the top displacement ratio of the pier to the support and the stiffness ratio of the series system to the pier is less than $20 \%$, and it reduces with the increase of the axial pressure ratio and interface contact strength. After the piers yield, the maximum difference between the top displacement ratio and the stiffness ratio of the series system is lower than $5 \%$. Therefore, the interface contact is strengthened to reduce the interface friction slip, the mechanical properties of the series system can be estimated by the existing mechanical model of the series system.

In summary, the interface contact condition between the support and adjacent structure can obviously affect the mechanical relationships of the series system, at the same time, it also affects the shear force and shear deformation of the rubber support and bridge pier. Under different interface contact condition, the failure modes of the series system are different. In order to reduce the damage to the bridge pier and avoid collapse, upper structure collision and beam falling, the interface connection strength should be adjusted to reduce superstructure sliding and horizontal force. In addition, in view of the interface contact condition, the failure modes, mechanics and safety of the local structure can be accuracy estimated.

\section{Acknowledgements}

This paper is supported jointly by the National Key Research and Development Project of China (2017YFE0103000), National Natural Science Foundation of China (51608238), and Innovation Fund Project of the Research Institute of Highway Science of the Ministry of Transport
Numerical Simulation of Mechanical Properties of Series System With Bearing and Pier Under Lateral Load 
"Study on Robustness Analysis Method of the Serviced Beam Bridge Based on the Vulnerable Component" (2019-C114).

\section{Funding}

This work was supported by the Ministry of Science and Technology under the National Key Research and Development Project of China (2017YFE0103000; National Natural Science Foundation of China under youth fund (51608238); Research Institute of Highway Science of the Ministry of Transport under Innovation Fund Project (2019-C114).

\section{REFERENCES}

Buckle, I., Nagarajaiah, S., \& Ferrell, K. (2002). Stability of Elastomeric Isolation Bearings: Experimental Study. Journal of Structural Engineering, 128(1), 3-11. https://doi.org/10.1061/40558(2001)111

Cardone, D., \& Perrone, G. (2010). Critical Load of Slender Elastomeric Seismic Isolators: An Experimental Perspective. Engineering Structures, 40, 198-204. https://doi.org/10.1016/j.engstruct.2012.02.031

Chen, S. C., Tian, X. K., Yan, W. M., \& Kim, K. S. (2014). Modeling and Analysis of Laminated Rubber Bearing Under Axial Tensile Loading. Material and Structures, 47(6), 987-997. https://doi.org/10.1617/s11527-013-0108-3

Du, Y. F., Wu, Z. T., \& Fan, P. P. (2013). Parametric Analysis and Calculation Formula for Horizontal Stiffness of Series Isolation System. Journal of Vibration and Shock, 32(23), 64-69. [In Chinese].

Du, Y. F., Zhu, Q. K., \& Li, H. (2011). Analysis of Large Deformation Behavior of Series Isolation System and Its Experimental Verification. Journal of Vibration and Shock, 30(11), 236-239. [In Chinese].

Gauron, O., Saidou, A., Busson, A., Siqueira, G. H., \& Paultre, P. (2018). Experimental Determination of the Lateral Stability and Shear Failure Limit States of Bridge Rubber Bearings. Engineering Structures, 174, 39-48. https://doi.org/10.1016/j.engstruct.2018.07.039

Han, M., Zhang, Y. J., \& Du, H. K. (2017). Test Study on Shear Performance of Small Laminated Rubber Bearing. Earthquake Resistant Engineering and Retrofitting, 2(39), 110-115. [In Chinese].

JTG/T B02-01-2008. (2008). Guidelines for Seismic Design of Highway Bridges. Beijing: People's transport press (Chongqing transportation research and design institute). [In Chinese].

Khan, A. K. M. T. A., Bhuiyan, M. A. R., \& Ali, S. B. (2019). Seismic Responses of a Bridge Pier Isolated by High Damping Rubber Bearing: Effect of Rheology Modeling. International Journal of Civil Engineering, 17(11), 1767-1783. https://doi.org/10.1007/s40999-019-00454-x 
Kikuchi, M., Nakamura, T., \& Aiken, I. D. (2010). Three-Dimensional Analysis for Square Seismic Isolation Bearings Under Large Shear Deformations and High Axial Loads. Earthquake Engineering and Structural Dynamics, 39(13), 1513-1531. https://doi.org/10.1002/eqe.1042

Konstantinidis, D., Kelly, J. M., \& Makris, N. (2008). Experimental Investigation on the Seismic Response of Bridge Bearings. Report number EERC 2008-02. USA: University of California Berkeley.

Li, Y., Li, C., \& Li, Q. (2014). Effect of Elastomeric Bearings Slide on Seismic Performance of Small and Medium Span Girder Bridges in Earthquake. China Civil Engineering Journal, 47(S1), 124-129. [In Chinese].

Montuori, G. M., Mele, E., Marrazzo, G., \& Brandonisio, G. (2016). Stability Issues and Pressure-Shear Interaction in Elastomeric Bearings: The Primary Role of the Secondary Shape Factor. Bulletin of Earthquake Engineering, 14(2), 569-597. https://doi.org/10.1007/s10518-015-9819-x

Saadatnia, M., Riahi, H. T., \& Izadinia, M. (2019). Hysteretic Behavior of Rubber Bearing With Yielding Shear Devices. International Journal of Steel Structures, 19(3), 747-759. https://doi.org/10.1007/s13296-018-0159-y

Wu, G., Wang, K. H., Li, C. et al. (2014). Parametric Finite Element Investigation of Laminated Rubber Bearings With Friction Slipping. China Civil Engineering Journal, 47(S1), 108-112. [In Chinese].

Wu, Y. F., Wang, H., Li, A. Q., Feng, D. M., \& Sha, B. (2017). Explicit Finite Element Analysis and Experimental Verification of a Sliding Lead Rubber Bearing. Journal od Zhejiang University-Science A, 18(5), 363-376. https://doi.org/10.1631/jzus.a1600302

Xing, N. L., Cui, X. X., \& Li, J. Z. (2016). Experimental Study on Sliding Friction Behavior of Laminated Rubber Bearing and Its Mechanical Model. Journal of TongJi University (Natural Science and its Mechanical Model), 12(44), 1828-1834. [In Chinese].

Xing, N., \& Li, J. (2017). Experimental and Numerical Study on Seismic Sliding Mechanism of Laminated-Rubber Bearings. Engineering Structures, 141, 159-174. [In Chinese]. https://doi.org/10.1016/j.engstruct.2017.03.032

Yamamoto, S., Kikuchi, M., Ueda, M., \& Aiken, I. D. (2009). A Mechanical Model for Elastomeric Seismic Isolation Bearings Including the Influence of Axial Load. Earthquake Engineering and Structural Dynamics, 38(2), 157-180. https://doi.org/10.1002/eqe.847

Yan, D. H., Dong, D. F., Chen, C. S., \& Tu, G. Y. (2017). Nonlinear Coupling Analysis Considering Dynamic and Static Friction Effect for Large Travel Sliding Bearing. Journal of Chang'an University (Natural Science Edition), 37(2), 45-54. [In Chinese].

Zhou, X. Y., Han, M., Zeng, D. M. (1999). Horizontal Rigidity Coefficient of the Serial System of Rubber Bearing with Column. Journal of Vibration and Shock, 12(2), 157-165. [In Chinese].
Pengfei Li

Numerical Simulation of Mechanical

Properties of Series

System With Bearing and Pier Under Lateral Load 